\title{
Comparison of the Real-Time PCR Tests for Factor V G1691A and Prothrombin G20210A with PCR- Restriction Fragment Length Polymorphism and Direct Sequencing Tests
}

Hyunjung Kim ${ }^{1}$, Gun Dong Lee ${ }^{1,2}$, Sang Yoon Lee ${ }^{1,2}$, Woori Jang ${ }^{1,2}$, Joonhong Park $^{1,2}$, Hyojin Chae ${ }^{1,2}$, Myungshin $\mathrm{Kim}^{1,2}$, and Yonggoo Kim $^{1,2}$

${ }^{1}$ Department of Laboratory Medicine and ${ }^{2}$ Catholic Genetic Laboratory Center, The Catholic University of Korea College of Medicine, Seoul, Korea

\section{Corresponding author:} Myungshin Kim

Department of Laboratory Medicine, Seoul St. Mary's Hospital, 222 Banpo-daero, Seocho-gu, Seoul 137-701, Korea. Tel: +82-2-2258-1645

Fax: +82-2-2258-1719

E-mail: microkim@catholic.ac.kr

pISSN: 1225-097X

eISSN: 2288-7261
Background: Factor V (FV) G1691A and prothrombin G20210A mutations are the most common targets of genetic tests for thromboembolism. This study compared the ability of real-time PCR to detect FV G1691A and prothrombin G20210A (BioSewoom, Korea) with that of PCR-restriction fragment length polymorphism (RFLP) and direct sequencing, to evaluate diagnostic equivalency.

Methods: Real-time PCR was compared with PCR-restriction fragment length polymorphism (RFLP) and direct sequencing using patients' samples as well as heterozygous and homozygous World Health Organization (WHO) reference reagent DNA. The limit of detection (LoD) for real-time PCR was determined using WHO reference reagents.

Results: All 141 and 156 patient samples were tested for the FV G1691A and prothrombin G20210A mutations, respectively; the results from all three methods (real-time PCR, PCRRFLP, and direct sequencing) consistently showed that the samples were wild type. Each of the three methods showed the same results in tests using heterozygous and homozygous DNA from the WHO reference reagents. The LoD of wild type and homozygous samples was $65.16 \mathrm{pg} / \mu \mathrm{L}$ for FV G1691A, and $61.3 \mathrm{pg} / \mu \mathrm{L}$ for prothrombin G20210A. The LoD of heterozygous samples was $1,650.0 \mathrm{pg} / \mu \mathrm{L}$ for FV G1691A and $1,640.0 \mathrm{pg} / \mu \mathrm{L}$ for prothrombin G20210A.

Conclusions: The real-time PCR test kits for FV G1691A and prothrombin G20210A showed reliable equivalency with PCR-RFLP and direct sequencing, and could be useful tests to detect gene polymorphisms for thromboembolism.

(J Lab Med Qual Assur 2015;37:37-43)

Key Words: Real-time polymerase chain reaction, Factor V G1691A, Prothrombin G20210A, Thrombophilic mutation, Factor V Leiden

Received December 17, 2014, Revision received February 10, 2015, Accepted February 23, 2015
서론

혈전증(thrombosis) 환자에서 원인이 되는 요인을 파악하 기 위해서, 그리고 적절한 치료방침을 세우기 위해서 혈전증 의 위험도 평가검사가 필요하다. 또한 환자의 가족인 경우에 도 위험도를 사전에 평가하여 예방적 투약의 필요성을 결정하 기 위해서 검사가 필요하다. 혈전증은 혈류의 정체, 혈관 내벽 의 손상, 과응고성이 야기되는 여러 가지 임상적 상황들과 연 계되어 발생하게 된다. 그리고 선천적으로 혈액의 과응고성을
가지게 되는 유전학적인 이상을 가지고 있으면 혈전증 발생 위 험도가 높아지게 된다. 유전성 혈전증의 원인에는 factor $\mathrm{V}$ 돌 연변이로 인해 활성화 C단백 저항성이 생기는 경우, factor II (prothrombin) 돌연변이에 의한 prothrombin 기능 증가, 그 리고 항트롬빈, C단백, S단백의 돌연변이가 발생하여 자연 항 응고체계의 결핍이 생기는 경우 등이 있다.

이 중에서 factor V G1691A와 prothrombin G20210A 가 가장 흔하게 검사되는 유전성 혈전증 검사이다. factor $\mathrm{V}$ G1691A 돌연변이는 factor V의 1691번 뉴클레오티드에 점돌 


\title{
Journal of LABORATORY MEDICINE and QUALITY ASSURANCE
}

\author{
Hyunjung Kim et al • Real-Time PCR Thrombophilia Mutation Tests
}

연변이로 인해 아르기닌 아미노산이 글루타민으로 치환된 것 (R506Q)이다[1]. 그 결과로 활성 C단백의 항응고 작용에 저 항성(resistance)이 나타나서 응고가 촉진되게 되며 factor V Leiden이라고 한다. 백인 정맥혈전증 환자의 $10 \%$ 정도에 서 factor V G1691A 돌연변이가 나타난다[2]. Heterozygote type 돌연변이를 가진 사람은 정맥혈전증의 위험도가 4-7배 증가하며, homozygote type 돌연변이를 가진 사람은 11-25배 정도의 위험도가 증가한다[3-5].

Prothrombin G20210A 돌연변이는 prothrombin 유전자의 3’ 비해독 부위의 20210 위치에서 점 돌연변이가 생긴 것으로, 그 결과로 prothrombin 농도가 증가하여 정맥혈전증 위험도 가 상승한다[6]. Prothrombin G20210A 돌연변이의 발생률 은 정맥혈전증 환자에서는 $19 \%$ 정도이며 일반인구집단에서 는 0-2\% 정도로 알려져 있다[7]. Prothrombin G20210A 돌 연변이가 있는 사람은 정맥혈전증 발생 위험도가 2.7 배 정도 상승하는 것으로 보고되었다[5].

그리고 두 유전자변이는 임산부에서 정맥혈전증의 위험도도 증가시키는 것으로 알려졌으며, factor V G1691A 존재 시는 9배, prothrombin G20210A 존재 시는 15배, 두 가지 유전자 변이 모두 존재 시는 100 배 이상 증가하는 것으로 보고되었다 [8].

혈전증과 관련된 유전자 변이 검출방법으로는 제한효 소절단길이다형분석(PCR-restriction fragment length polymorphism, PCR-RFLP), 직접염기서열분석, real-time $\mathrm{PCR}$, multiplex PCR과 DNA microarray 등의 검사들이 개 발되었다[9-12]. 이 중에서 유전성 혈전증검사를 위해 사용 된 고식적인 방법은 PCR-RFLP인데, 이 방법은 검사시간이 길고 숙련된 검사자가 필요하다. 가장 정확한 방법(reference method)이라 할 수 있는 직접염기서열분석도 검사시간이 길 며 비용이 비싸다는 단점이 있다. Real-time PCR은 간편하고, 검사실 오염위험이 낮으며, 빠르고 정확하게 점 돌연변이를 검 출할 수 있는 방법이다.

본 연구에서는 real-time PCR 원리를 이용하여 factor V G1691A 및 prothrombin G20210A를 분석하는 검사법을 기 존의 방법인 PCR-RFLP 및 직접염기서열분석을 비교하여 성 능을 평가하고 임상적 이용 가능성을 알아보고자 하였다.

\section{재료 및 방법}

2011년 9월부터 2014년 3월까지 서울성모병원에 factor V G1691A와 prothrombin G20210A 돌연변이검사를 의뢰 한 환자의 검사 후 남은 DNA를 사용하였다. 본 연구는 가톨
릭중앙의료원 연구윤리사무국의 승인을 받아서 진행하였다 (KC14SNSI0062).

그리고 환자 검체 $\mathrm{DNA}$ 를 대상으로 real-time $\mathrm{PCR}$ 을 이 용한 유전형분석과 PCR-RFLP 및 직접염기서열분석 간 비 교검사를 시행하였다. 두 유전자변이의 표준물질인 World Health Organization (WHO) reference reagent factor $\mathrm{V}$ Leiden, human gDNA, 1st international genetic reference panel (NIBSC code 04/224) (F5 WHO reference DNA) 과 prothrombin mutation G20210A, human g DNA, 1st international genetic reference panel (NIBSC code 05/130) (F2 WHO reference DNA)을 사용하여 비교평가에 사용하였 다. 각각의 물질은 wild type, heterozygous, homozygous의 세 가지 유전형으로 구성되어 있으며, 이 중에서 heterozygous type, homozygous type DNA를 사용하여 각각 2회씩 비교 검사를 실시하였다. $\mathrm{PCR}$ 을 위한 $\mathrm{DNA}$ 는 $\mathrm{EDTA}$ 전혈에서 QIAamp DNA blood mini kit (QIAGEN GmbH, Hilden, Germany)를 이용하여 제조사에서 권장하는 방법대로 추출하 였고, 최종 DNA 농도는 $50 \mathrm{ng} / \mu \mathrm{L}$ 로 조정하였다.

\section{Real-time PCR}

Real-time PCR을 이용한 factor V G1691A와 prothrombin G20210A 분석은 hydrolysis probe 원리를 이용해 설계 된 real-Q factor V Leiden G1691A kit와 prothrombin G20210A kit (BioSewoon, Seoul, Korea)를 이용하였다. 돌 연변이 검출에 사용되는 보고 표지자(reporter dye)는 프루브 의 $5^{\prime}$ 말단에 부착되어 있으며 6-carboxyfluorescein (FAM) 과 $\mathrm{VIC}$ 가 사용되었는데, FAM은 wild type에 붙고 VIC 는 mutant type에 결합한다. Minor-groove binding non fluorescent quencher (MGBNFQ)는 퀀처 표지자(quencher dye)로 프루브의 3' 말단에 부착되어 있다. PCR 마스터 혼합 물 $21 \mu \mathrm{L}$ 과 DNA $4 \mu \mathrm{L}$ 를 섞은 후, Rotor-gene Q (Qiagen, Hilden, German)를 이용하여 real-time PCR을 시행하였 다. $\mathrm{PCR}$ 조건은 $50^{\circ} \mathrm{C}$ 에서 2 분, $95^{\circ} \mathrm{C}$ 에서 10 분 후, $60^{\circ} \mathrm{C} 30$ 초, $95^{\circ} \mathrm{C} 15$ 초, $66^{\circ} \mathrm{C} 45$ 초로 40 번 반복 진행하였다. 대조물질 3 개(wild, homozygous, heterozygote types)를 매 검사당 1 회씩 동시에 시행하였다. 검사판독을 위한 역치(threshold) 는 F5와 F2의 WHO reference DNA 각각의 wild type, homogenous type, heterozygous type 세 가지 모두 사용되었 으며, homogenous type, heterozygous type DNA의 경우는 직접 희석하여 $10,100,1,000,10,000,100,000 \mathrm{pg} / \mu \mathrm{L}$ 의 5 단 계로 제조하여 5 번씩 측정하였다. 각각의 검사에서 모든 농도 의 증폭 그래프 동시에 나타낸 후, baseline의 제일 높은 지점 
의 형광량을 $0 \%$, 가장 먼저 증폭을 나타낸 검체의 가장 높은 형광량을 $100 \%$ 정한 후, $32.5 \%$ 되는 부분의 형광량을 산출하 여 역치로 정하였다[13]. Factor V G1691A와 prothrombin G20210A 두 검사의 역치는 모두 0.2 fluorescence였다.

\section{PCR-Restriction Fragment Length Polymorphism}

PCR-RFLP 검사에 사용된 primer 염기서열은 factor $\mathrm{V}$ G1691A에 대해서는 forward: 5'TGCCCAGTGCTTAAC AAGACCA-3', reverse: 5'-TGTTATCACACTGGTGC TAA-3', 그리고 prothrombin G20210A에 대해서는 5' -ATGGGGTGAAGGCTGTGACC-3’, reverse: 5’AGCACTGGGAGCATTGAGCCT-3'이었다. 추출한 DNA (농도 $50 \mathrm{ng} / \mu \mathrm{L}$ ) $5 \mu \mathrm{L}$ 를 $\mathrm{PCR}$ 반응혼합물과 섞은 후 $\mathrm{C} 1000$ Touch thermal cycler (Bio-Rad laboratories Inc., Hercules, $\mathrm{CA}, \mathrm{USA}$ )로 $\mathrm{PCR}$ 을 진행하였다. $\mathrm{PCR}$ 조건은 $95^{\circ} \mathrm{C}$ 에서 5 분, $95^{\circ} \mathrm{C} 30$ 초, $60^{\circ} \mathrm{C} 30$ 초, $72^{\circ} \mathrm{C}$ 에서 1 분으로 35 반복 후, $72^{\circ} \mathrm{C}$ 에서 5 분간으로 진행하였다. 1 차 $\mathrm{PCR}$ 후 $20 \mu \mathrm{L}$ 증폭산물과 $\mathrm{Mnl1}$ 제한효소 혼합물을 $5 \mu \mathrm{L}$ 씩 혼합한 후, $37^{\circ} \mathrm{C}$ 에서 6 시간 반응시켰으며, 제한효소 처리가 끝난 증폭산물 $10 \mu \mathrm{L}$ 를 $4 \%$

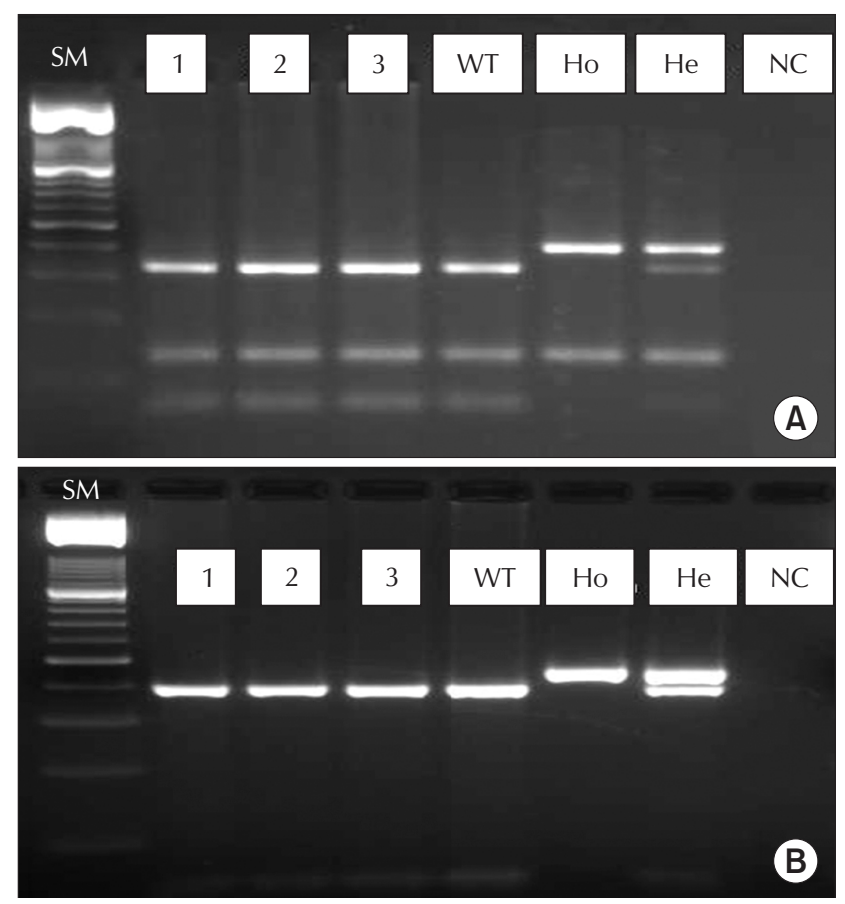

Fig. 1. Results of PCR-RFLP test for (A) factor V G1691A and (B) prothrombin G20210A 1, 2, and 3: wild type patients. Abbreviations: WT, wild type; Ho, homozygous; He, heterzygous; NC, negative control; SM, size marker.
아가로즈 겔에 전기 영동한 후 wild type, homogenous type, heterozygous type을 확인하였다(Fig. 1).

\section{3. 염기서열분석}

PCR-RFLP의 1차 PCR 증폭산물을 BigDye Terminator v3.1 Cycle Sequencing 키트(Applied Biosystems, Foster City, CA, USA)를 이용하여 양방향으로 염기서열분석을 시행 하였다. 사용된 장비는 ABI PRISM 3130 Genetic Analyzer (Applied Biosystems)이며 크로마토그램(chromatograms) 은 Sequencher software ver. 4.9 프로그램(Gene Codes, Ann Arbor, MI, USA)을 이용하여 분석하였다. 결과는 coagulation factor $\mathrm{V}$ (F5)와 factor II (F2)의 참고서열로 각각 NM_000130.4과 NG_008953.1를 사용하여 factor V G1691A와 prothrombin G20210A 돌연변이가 있는지 관찰하 였다.

\section{4. 최소검출한계의 평가}

Real-time PCR을 이용한 factor V G1691A와 prothrombin G20210A 검사는 정성검사이지만 유전자변이 정도가 어느 농 도 수준에서부터 양성으로 검출할 수 있는지 파악하고, 기초 데이터를 제공하기 위해서 F5 WHO reference DNA와 F2 $\mathrm{WHO}$ reference DNA를 이용하여 분석민감도를 평가하였다. 각각 표준물질은 wild type, homogenous type, heterozygous type 세 가지 모두 사용되었으며, 직접 희석하여 10,100 , $1,000,10,000,100,000 \mathrm{pg} / \mu \mathrm{L}$ 의 5단계로 제조하였다. 이 물질 들은 각각 12 일에 거쳐 하루 2 번씩 총 24 회 반복 측정하였고 양성률을 산출하였다. 최소검출한계(limit of detection, $\mathrm{LoD}$ ) 는 StatPlus 2009 program (AnalystSoft, Alexandria, VA, USA)을 이용하여 95\% probit 분석법( $95 \%$ 양성률을 나타낼 것으로 예상되는 최소 농도)으로 구하였다. 추가적으로 연구 기간 중 가톨릭대학교 서울성모병원에서 연구기간 중 의뢰된 두 검사의 양성률과 나이, 성별을 조사하였다. 해당 기간 검사 는 PCR- RFLP로 시행하였다.

\section{결과}

Factor V G1691A 돌연변이 검사는 141 개의 환자 검체와 F5 WHO reference DNA, heterozygous type, homozygous type를 사용하여 비교검사를 시행하였다. 환자 검체는 realtime PCR, PCR-RFLP 및 직접염기서열분석에서 모두 wild type으로 확인되었고, WHO reference DNA 검체는 각각 2회 검사에서 모두 일치하게 결과가 확인되었다(Table 1). 
Journal of LABORATORY MEDICINE and QUALITY ASSURANCE

Hyunjung Kim et al • Real-Time PCR Thrombophilia Mutation Tests

Table 1. Comparison of the real-time PCR tests for factor V G1691A and prothrombin G20210A with PCR-RFLP and direct sequencing tests

\begin{tabular}{|c|c|c|c|c|c|c|}
\hline \multirow{2}{*}{ Variable } & \multicolumn{3}{|c|}{ Factor V G1691A } & \multicolumn{3}{|c|}{ Prothrombin G20210A } \\
\hline & Wild type & Heterozygous & Homozygous & Wild type & Heterozygous & Homozygous \\
\hline \multicolumn{7}{|l|}{ Patients' samples } \\
\hline Real-time PCR & 141 & 0 & 0 & 156 & 0 & 0 \\
\hline PCR-RFLP & 141 & 0 & 0 & 156 & 0 & 0 \\
\hline Direct sequencing & 141 & 0 & 0 & 156 & 0 & 0 \\
\hline \multicolumn{7}{|c|}{ World Health Organization reference reagents* } \\
\hline Real-time PCR & - & 2 & 2 & - & 2 & 2 \\
\hline PCR-RFLP & - & 2 & 2 & - & 2 & 2 \\
\hline Direct sequencing & - & 2 & 2 & - & 2 & 2 \\
\hline
\end{tabular}

Abbreviation: RFLP, restriction fragment length polymorphism.

${ }^{*}$ Factor V Leiden, human gDNA, 1st international genetic reference panel (NIBSC code 04/224) and prothrombin mutation G20210A, human g DNA, 1st international genetic reference panel (NIBSC code 05/130).

Table 2. Positive signal rates (\%) of 24 repeats and LoD of mutation in each genotype for the real-time PCR kits testing for factor V G1691A and prothrombin G20210A

\begin{tabular}{|c|c|c|c|c|c|c|}
\hline \multirow{2}{*}{ Variable } & \multicolumn{3}{|c|}{ Factor V G1691A } & \multicolumn{3}{|c|}{ Prothrombin G20210A } \\
\hline & Wild type & Homozygous & Heterozygous & Wild type & Homozygous & Heterozygous \\
\hline $10^{5}(\mathrm{pg} / \mu \mathrm{L})$ & 100.0 & 100.0 & 100.0 & 100.0 & 100.0 & 100.0 \\
\hline $10^{4}(\mathrm{pg} / \mu \mathrm{L})$ & 100.0 & 100.0 & 100.0 & 100.0 & 100.0 & 100.0 \\
\hline $10^{3}(\mathrm{pg} / \mu \mathrm{L})$ & 100.0 & 100.0 & 100.0 & 100.0 & 100.0 & 100.0 \\
\hline $10^{2}(\mathrm{pg} / \mu \mathrm{L})$ & 100.0 & 100.0 & 75.0 & 100.0 & 100.0 & 79.1 \\
\hline $10(\mathrm{pg} / \mu \mathrm{L})$ & 79.1 & 79.1 & 0.08 & 83.3 & 83.3 & 0.08 \\
\hline $\operatorname{LoD}(\mathrm{pg} / \mu \mathrm{L})^{*}$ & 65.16 & 65.16 & $1,650.0$ & 61.3 & 61.3 & $1,640.0$ \\
\hline
\end{tabular}

Abbreviation: LoD, limit of detection.

${ }^{\star}$ LoD were defined by $95 \%$ probit analysis using StatPlus 2009 software (AnalystSoft, USA).

Prothrombin G20210A 돌연변이 검사에서도 156 개의 환 자 검체는 세 검사 모두에서 wild type으로 일치하였다. F2 WHO reference DNA, heterozygous type, homozygous type를 이용한 비교검사에서도 $100 \%$ 일치하는 결과를 확인 할 수 있었다(Table 1).

$95 \%$ probit 분석법을 이용해 산출한 real-time PCR 검사 의 LoD 값은, factor V G1691A의 wild type과 homozygous type에서는 $65.16 \mathrm{pg} / \mu \mathrm{L}$, heterozygote type에서는 1,650 $\mathrm{pg} / \mu \mathrm{L}$ 이었다(Table 2). Prothrombin G20210A의 LoD 는 wild type와 homozygous type에서는 $61.3 \mathrm{pg} / \mu \mathrm{L}$, heterozygote type에서는 $1,640 \mathrm{pg} / \mu \mathrm{L}$ 이었다.

임상에서 의뢰한 factor V G1691A 검사는 1,428명(남 817 명, 여 611명), prothrombin G20210A 검사는 1,022명(남 581
명, 여 441명)이었으며, 각각의 검사를 시행한 환자군의 나이

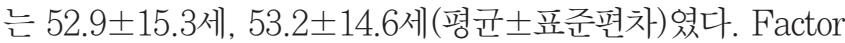
V G1691A 검사는 1,428명 모두 음성 결과(wild type)가 나왔 고, prothrombin G20210A는 두 명의 heterozygous type을 제외하고 모두 wild type 결과를 보였다. Heterozygous type 을 나타낸 두 명의 환자는 모두 외국인 여성이었다. 환자들의 나이는 27,28 세였고, 진단명은 신장정맥 혈전증(renal vein thrombosis)과 뇌경색(cerebral infarction)이었다.

\section{고찰}

혈전증의 선별검사가 필요한 경우는 정맥혈전증, 유산, 임신 중독증(preeclampsia), 자궁 내 발육지연(intrauterine fetal 


\section{Journal of LABORATORY MEDICINE and QUALITY ASSURANCE}

\section{Hyunjung Kim et al • Real-Time PCR Thrombophilia Mutation Tests}

growth retardation), 태반조기박리(abruption placentae), 그리고 혈전증 위험 유전자 이상을 가지고 있는 직계가족이 있 는 사람, 정맥혈전증의 가족력이 있으면서 경구용 피임제 복용 혹은 호르몬 치료 중인 사람 등이 해당된다[14].

PCR-RFLP이 고식적인 표준방법으로 쓰여졌지만, 많은 양의 DNA가 필요하며 자동화가 불가능하고, 시간과 비용 이 많이 소모된다. 또한 기술적으로 숙련된 검사자가 필요하 고 probe/enzyme 조합을 각각 다르게 제조해 하는 경우가 있 으며, 겔을 이용한 분석방법은 검사실 오염 위험도가 높은 단 점이 있다. 최근에 multiplex PCR-RFLP 검사가 소개되었 지만 여전히 PCR- RFLP의 단점을 가지고 있는 방법들이다 $[12,15]$.

근래에 개발된 real-time PCR은 간편하고 빠르고 민감도가 높은 검사방법으로 사용도가 증가되고 있다. 정량까지 가능한 장점이 있으며 PCR 반응이 진행되면서 동시에 형광량을 측정 하기 때문에 검사실 오염의 위험도가 낮은 장점이 있다. Realtime PCR은 형광 검출 원리에 따라서 melting curve 분석, dual hybridization, hydrolysis (TaqMan), scorpions probe 등이 있다. 본 연구에서 평가한 FV G1691A와 prothrombin G20210A 돌연변이 검출을 위한 real-time PCR 검사는 hydrolysis probe를 이용하며 두 종류의 fluorescent allelespecific probe와 한 쌍의 PCR primer를 사용한다. 한 개의 fluorescent probe는 homozygous type 검출을 위한 것이며 다른 한 개의 fluorescent probe는 wild type을 검출하기 위한 것이다. Heterozygous type에서는 두 개의 형광시그널이 모 두 검출된다.

이전의 연구에서 유전성 혈전증 검사를 위한 $\mathrm{PCR}$ 검 사들의 비교검사 결과 일치도가 $100 \%$ 가 되지 않은 경우 도 보고되었다. Factor V G1691A 검사의 비교평가의 경 우 fluorescence resonance energy transfer (invader), nanochip electronic microarray, oligonucleotide hybiridization assay, temperature gradient capillary electrophoresis, electrochemical genosensor 검사법의 경우 는 PCR-RFLP와의 일치율이 93-100\%로 100\% 일치하지 않 은 경우가 더 많이 보고되었으며, melting curve analysis나 TaqMan real-time PCR, MAIDI-TOF mass spectrometry, pyrosequencing, reverse allele specific oligonucleotide hybridization assay, MGBNFQ real-time PCR 등의 방법 은 $100 \%$ 일치율을 보였다[16]. Prothrombin G20210A 검사 의 비교평가 경우도 rolling circle amplification assay, first nucleotide change technology 검사의 경우 PCR-RFLP와 $100 \%$ 일치율을 보이지 않았으며(일치율 98-99\%), TaqMan real-time PCR, Electro-chemical Detection, MALDI-TOF Mass Spectrometry, Nanochip Electronic Microarray MGBNFQ real-time PCR 등은 $100 \%$ 일치율을 보였다[16]. Factor V G1691A와 prothrombin G20210A를 동시에 검출 하는 multiplex-PCR의 경우 대부분 PCR-RFLP와 $100 \%$ 일 치율을 보였다[16]. 불일치의 원인으로는 가능성이 있는 것 은 검사자의 실수나 일부의 PCR방법은 잠재성 다형성(silent polymorphism)으로 인해 위양성이 나타날 수도 있으며, 검사 방법 간 검출민감도나 정확도의 차이로 발생할 수도 있다[16]. 본 연구에서 factor V G1691A와 prothrombin G20210A real-time PCR 돌연변이 검사법은 이전의 real-rime PCR의 비교평가연구와 마찬가지로 $\mathrm{PCR}-\mathrm{RFLP}$ 과 직접염기서열분석 과 $100 \%$ 의 일치율을 보였다.

$\mathrm{LoD}$ 는 면역화학검사법에서는 통상적으로 쓰이는 평가기준 이며, 근래 들어서 분자생물학 분야에서도 검사실에서 초기 도 입 시 검사해보도록 권장하고 있다[17]. Factor V G1691A과 prothrombin G20210A의 분자생물학적 검출방법에 대해 그 동안의 논문에서는 $\mathrm{LoD}$ 설정평가가 이루어지지 않았지만 본 연구에서는 F2과 F5 WHO reference DNA의 각 유전형별로 평가하였고, wild type과 homozygous type보다 heterozygous type의 LoD가 높게 나타났다. 이는 heterozygous type의 경 우 wild type과 mutant type의 allele sequence가 같이 존재 하기 때문에 두 개의 형광물질에서 각각 검출되려면 역치에 도달하기 위해 더 많은 농도의 sequence가 필요하기 때문이 다. 한국인에서 factor V G1691A와 prothrombin G20210A 돌연변이 양성 환자는 이전 연구에서 보고되지 않았으며, 본 연구에서도 한국인에서는 두 검사 모두 양성 환자는 없었다 $\lceil 18,19]$.

결론적으로 real-time PCR 원리를 이용한 factor V G1691A와 prothrombin G20210A 검사는 기존의 방법인 PCR-RFLP와 직접염기서열분석과 $100 \%$ 일치율을 보여 신 뢰할만한 정확도를 지닌 검사로서, 유전성 혈전증의 예방, 진 단 및 치료에 도움을 줄 수 있을 것으로 생각된다.

\section{감사의 글}

본 연구는 보건복지부 보건의료연구개발사업의 지원에 의하 여 이루어졌다(HI10C2020).

\section{REFERENCES}

1. Dahlback B. New molecular insights into the genetics of 


\section{Journal of LABORATORY MEDICINE and QUALITY ASSURANCE}

Hyunjung Kim et al • Real-Time PCR Thrombophilia Mutation Tests

thrombophilia: resistance to activated protein $\mathrm{C}$ caused by Arg506 to Gln mutation in factor V as a pathogenic risk factor for venous thrombosis. Thromb Haemost 1995;74:139-48.

2. Hooper WC, Dilley A, Ribeiro MJ, Benson J, Austin H, Silva $\mathrm{V}$, et al. A racial difference in the prevalence of the Arg506-->Gln mutation. Thromb Res 1996;81:577-81.

3. Cordoba I, Pegenaute C, Gonzalez-Lopez TJ, Chillon C, Sarasquete ME, Martin-Herrero F, et al. Risk of placentamediated pregnancy complications or pregnancy-related VTE in VTE-asymptomatic families of probands with VTE and heterozygosity for factor V Leiden or G20210 prothrombin mutation. Eur J Haematol 2012;89:250-5.

4. Saemundsson Y, Sveinsdottir SV, Svantesson H, Svensson PJ. Homozygous factor V Leiden and double heterozygosity for factor $\mathrm{V}$ Leiden and prothrombin mutation. J Thromb Thrombolysis 2013;36:324-31.

5. Simone B, De Stefano V, Leoncini E, Zacho J, Martinelli I, Emmerich J, et al. Risk of venous thromboembolism associated with single and combined effects of Factor V Leiden, Prothrombin 20210A and Methylenetethraydrofolate reductase C677T: a metaanalysis involving over 11,000 cases and 21,000 controls. Eur J Epidemiol 2013;28:621-47.

6. Poort SR, Rosendaal FR, Reitsma PH, Bertina RM. A common genetic variation in the 3 - -untranslated region of the prothrombin gene is associated with elevated plasma prothrombin levels and an increase in venous thrombosis. Blood 1996;88:3698-703.

7. Kapur RK, Mills LA, Spitzer SG, Hultin MB. A prothrombin gene mutation is significantly associated with venous thrombosis. Arterioscler Thromb Vasc Biol 1997;17:2875-9.

8. Gerhardt A, Scharf RE, Beckmann MW, Struve S, Bender HG, Pillny M, et al. Prothrombin and factor V mutations in women with a history of thrombosis during pregnancy and the puerperium. N Engl J Med 2000;342:374-80.

9. Tempfer CB, Riener EK, Hefler LA, Huber JC, Muendlein A. DNA microarray-based analysis of single nucleotide polymorphisms may be useful for assessing the risks and benefits of hormone therapy. Fertil Steril 2004;82:132-7.

10. Maher C, Crowley D, Cullen C, Wall C, Royston D, Fanning S. Double fluorescent-amplification refractory mutation detection (dF-ARMS) of the factor V Leiden and prothrombin mutations. Thromb Haemost 1999;81:76-80.

11. Bozikova A, Gabrikova D, Sovicova A, Behulova R, Macekova S, Boronova I, et al. The frequency of factor V Leiden and prothrombin G20210A mutations in Slovak and Roma (Gypsy) ethnic group of Eastern Slovakia. J Thromb Thrombolysis 2012;34:406-9.

12. Bagheri M, Rad IA. A multiplex allele specific polymerase chain reaction (MAS-PCR) for the detection of factor $\mathrm{V}$ Leiden and prothrombin G20210A. Maedica (Buchar) 2011;6:3-9.

13. Agilent Technologies. Introduction to quantitative PCR: method and application guide. http://www.chem.agilent. com/Library/brochures/Brochure_Guide\%20to\%20 QPCR_IN70200C.pdf (Accessed March, 2012).

14. De Stefano V, Rossi E, Paciaroni K, Leone G. Screening for inherited thrombophilia: indications and therapeutic implications. Haematologica 2002;87:1095-108.

15. Lucotte G, Champenois T. Duplex PCR-RFLP for simultaneous detection of factor $\mathrm{V}$ Leiden and prothrombin G20210A. Mol Cell Probes 2003;17:267-9.

16. Emadi A, Crim MT, Brotman DJ, Necochea AJ, Samal L, Wilson LM, et al. Analytic validity of genetic tests to identify factor V Leiden and prothrombin G20210A. Am J Hematol 2010;85:264-70.

17. Laboratory Medicine Foundation. Clinical Laboratory Accreditation Program in Korea, Inspection check list, Molecular diagnostics. http://lmf.or.kr/sub/catalog. php? CatNo $=65 \&$ OutLine $=$ menu0outline. Laboratory Medicine Foundation. (Accessed January, 2014).

18. Kim YW, Yoon KY, Park S, Shim YS, Cho HI, Park SS. Absence of factor V Leiden mutation in Koreans. Thromb Res 1997;86:181-2.

19. Song KS, Park YS, Kim HK, Choi JR. Absence of the prothrombin gene variant in Koreans. Thromb Haemost 1999;81:990. 
Factor V G1691A, Prothrombin G20210A Real Time PCR 검사법의 PCR-Restriction Fragment Length Polymorphism와 직접염기서열분석법과의 비교평가

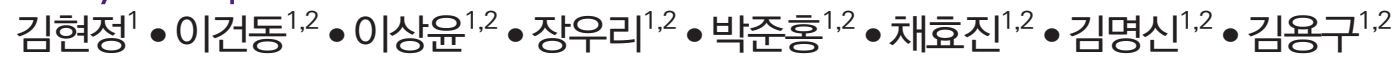
가톨릭대학교 의과대학 ${ }^{1}$ 진단검사의학교실, ${ }^{2}$ 가톨릭유전진단검사센터

배경: Factor V (FV) G1691A와 prothrombin G20210A 돌연변이는 가장 흔하게 검사되는 유전성 혈전증 검사이다. 본 연구에서는 real-time PCR 원리를 이용하여 이 두 가지 돌연변이를 분석하는 검사법을 기존의 방법인 PCR-RFLP 및 직접염기서열분석과 비교하여 성능을 평가하고 임상적 이용 가능성을 알아보고자 하였다.

방법: 환자 검체와 World Health Organization (WHO) 표준물질(heterozygous과 homozygous DNA)로 이용하여 real-time PCR 검사를 PCR-RFLP 및 직접염기서열분석 비교하였다. 그리고 $\mathrm{WHO}$ 표준물질을 이용하여 최소검출한계를 분석하였다.

결과: FV G1691A와 prothrombin G20210A 검사를 위해 각각 141개, 156 개의 환자 검체를 이용 하였는데 세 가지 검사법에서 모두 wild type 결과로 일치를 보였다. WHO 표준물질 heterozygous 과 homozygous DNA를 이용한 검사에서도 세 가지 검사법에서 모두 일치하였다. Wild type 과 homozygous types의 최소검출한계는 FV G1691A에서는 $65.16 \mathrm{pg} / \mu \mathrm{L}$, prothrombin $\mathrm{G} 20210 \mathrm{~A}$ 에서는 $61.3 \mathrm{pg} / \mu \mathrm{L}$ 이었다.

결론: FV G1691A와 prothrombin G20210A 돌연변이검사 real-time PCR은 기존의 방법인 $\mathrm{PCR}-\mathrm{RFLP}$ 와 직접염기서열분석과 신뢰할만한 동등성을 지닌 검사로서 유전성 혈전증의 진단에 도 움을 줄 수 있을 것으로 생각된다.

(J Lab Med Qual Assur 2015;37:37-43) 